\title{
Comparative study between the hemoprophylaxis provided by intra-articular and intravenous tranexamic acid in total knee arthroplasty
}

\author{
K.S. Kushalappa ${ }^{1, *}$, Vinay Kumar ${ }^{2}$, Vikram Shetty ${ }^{3}$, Lawerence Mathias ${ }^{4}$ \\ ${ }^{1}$ Junior Resident, ${ }^{2}$ Senior Resident, ${ }^{3,4}$ Professor, Dept. of Orthopaedics, K.S. Hegde Medical Academy, Mangalore, Karnataka, \\ India
}

*Corresponding Author: K.S. Kushalappa

Email: kushalappa.s@gmail.com

\begin{abstract}
Patients undergoing Total knee arthroplasty (TKR) are transfused at the rates of $11-21 \%$. As per ISHKS joint registry, data of 34,478 TKRs was assessed: Average age was 64.4 years These Geriatric patients are exposed to complications as a result of major orthopedic surgery and postoperative anemia, which exposes the patient to the complications associated with transfusion as well as increasing their duration of hospital stay. Geriatric patients are prone to existing comorbidities and are susceptible to risk factors, predisposing to Venous Thromboembolism (VTE). In our single center based short series study, we look to compare the efficacy of hemoprophylaxis provided by intravenous \& intra-articular tranexamic acid. Our aim is to find an effective protocol to reduce postoperative anemia whilst minimising risk of VTE's.
\end{abstract}

Keywords: TKA, Tranexamic acid, Chemoprophylaxis.

\section{Introduction}

A silver tsunami is approaching as the nation's population progresses towards a top heavy distribution. ${ }^{1}$ Life expectancy has increased steadily which points towards a progression towards development. The average Indian now can expect to live well into the $6^{\text {th }}$ decade of life, however, Geriatric problems are unavoidable and will ensue.

As Indians, we come from a culture oriented with activities which quite commonly require us to assume positions such as - squatting and sitting cross legged. From local village meetings to primary rural classrooms, to Indian style commodes which are believed to be good for bowel movements, but over the years; this position has proven to be a strain on the knees of the hard laboring Indian.

The country moves towards development and with that comes opportunities. The percentage of home or car loans has gone up year on year. People are more conscious of their lifestyle, health and standard of living than ever before. Protection, security and safety have now become necessities and this has made people aware of the concept and ease of access to insurance. Insurance in the medical world gives a patient a chance, an opportunity, to partake in state of the art elective procedures such as total joint replacement.

Joint replacement rates in India have soared in the recent past, the two factors that have primarily driven this increase are, availability of these procedures and acceptance for a culturally, "unpalatable" procedure. The Geriatric population look to live a longer, more productive, pain free life. The advancements in the medical industry in India gives Orthopaedic surgeons adequate support to deliver procedures which will enhance and lengthen one's productive life.

Geriatric patient prove a different challenge to the treating surgeon. From their fragile bony structure to their pre-existing comorbidities. Joint replacement surgery is a major Orthopaedics surgery that takes a toll on the patient. A balance is required to provide the patient with the best outcome at the most minimal collateral damage in terms of duration of hospital stay and financial impact.

Through our study, we look to provide an effective protocol in managing the perioperative blood loss that is accustomed by total knee arthroplasty. We aim to look at reducing the patient's hospital stay, financial burden and most importantly look to alleviate the risks associated with post-operative anemia and blood transfusion.

Tranexamic acid has been used to good effect in the past to control bleeding in other major Orthopaedic surgeries of the lower limb and in cardiac surgeries. Here we look to change the route of administration to bring about the same desired outcome at a lower cost to the patient in terms of side effects.

Study

Our study aimed at comparing the efficacy in hemoprophylaxis provided by intravenously and intraarticular administered tranexamic acid in cases of primary unilateral total knee arthroplasty. We compared the outcomes in terms of hemoglobin variations pre and postoperatively along with close monitoring for thromboembolic complications.

We included all patients undergoing primary unilateral total knee arthroplasty at our center from October 2015 to January 2017.

Patients were assessed based on total blood loss which was calculated based on an equation factoring hemoglobin variations during hospital stay and calculating the patient's' blood volume.

Patients were divided in two groups:

Group A- Patients received $10 \mathrm{mg} / \mathrm{kg}$ intravenous 
Tranexamic acid. First dose 10 minutes prior to tourniquet inflation. Second dose 3 hours following surgery.

Group B- Patients received 3 grams of tranexamic acid which was administered intra-articular following skin closure. Intra-articular drain was clamped prior to administration.

In both groups, intra-articular drain was maintained as per the operating surgeons protocol and the drains in both groups were clamped for a duration of 3 hours' postoperative. Group allocation was done through block randomisation.

Assessment of blood loss was done through the following equation as described by Good et $\mathrm{al}^{2}$ and Nadler et $\mathrm{al}^{3}$

Blood loss $($ in $\mathrm{mL})=100 \mathrm{~mL} / \mathrm{dL} \times \mathrm{Hgb} \mathrm{Loss} / \mathrm{Hgbi}$

Hgbloss $=\mathrm{BV} \times(\mathrm{Hgbi}-\mathrm{Hgbe}) \times 10 \mathrm{dL} / \mathrm{L}+\mathrm{Hgbt}$

$\mathrm{BV}=$ Estimated total body blood volume in liters

$=0.3669 \times \mathrm{H}^{3}+0.03219 \times \mathrm{W}+0.6041$ (for men), and

$=0.3561 \times \mathrm{H}^{3}+0.03308 \times \mathrm{W}+0.1833$ (for women)

$\mathrm{H}=$ Height in meters $\mathrm{W}=$ Body mass in $\mathrm{kg}$

$\mathrm{Hgbi}=\mathrm{Hgb}$ concentration prior to surgery (g/dL)

Hgbe $=\mathrm{Hgb}$ concentration nadir during hospital stay (g/dL)

Hgbt $=$ Total amount of allogeneic Hgb transfused $(\mathrm{g})$.

Values for the formula were collected as per the following protocol:

1. Pre-operative: Patients hemoglobin was estimated along with measurements of the patient's height in meters and weight in kilograms.

2. Post-operative: Hemoglobin was estimated at, zero hours, 6 hours, 12 hours and 24 hours' postoperative.

Data was collected and total blood loss was calculated as per the equation. Equation was weighted for female and male patients as suggested by previous authors.

Blood transfusion rates were noted among the study cohort, for which, a cut off lower limit hemoglobin value of $8 \mathrm{~g} \%$ was maintained and values below this, trigged immediate cross matched packed red cell transfusion in order to correct the post-operative anemia. (Hgbt values were calculated)

Each patient was closely monitored during their hospital stay for thromboembolic events which continued during outpatient department follows up till 4 weeks' post-operative. Uncertainties of deep venous thrombosis were assessed by venous Doppler done at our radiology department and was treated accordingly.

\section{Results}

Table 1: Independent students t test used to compare the two groups

\begin{tabular}{|c|c|c|c|c|c|c|c|}
\hline & $\begin{array}{c}\text { Route of } \\
\text { Administration }\end{array}$ & $\mathbf{N}$ & Mean & $\begin{array}{c}\text { Std. } \\
\text { Deviation }\end{array}$ & $\mathbf{t}$ & df & P Value \\
\hline \multirow[t]{2}{*}{ Blood Loss in $\mathrm{ml}$} & Intra articular & 27 & 463.7983 & 213.2829 & \multirow{2}{*}{$\begin{array}{c}- \\
2.843\end{array}$} & \multirow[t]{2}{*}{48} & \multirow[t]{2}{*}{0.007} \\
\hline & Intra venous & 23 & 656.8589 & 266.883 & & & \\
\hline \multirow[t]{2}{*}{$\mathrm{BV}$} & Intra articular & 27 & 4.177532 & 0.632619 & \multirow{2}{*}{0.642} & \multirow[t]{2}{*}{48} & \multirow[t]{2}{*}{0.524} \\
\hline & Intra venous & 23 & 4.280515 & 0.473883 & & & \\
\hline \multirow[t]{2}{*}{$\mathrm{Hb}$ loss } & Intra articular & 27 & 56.63665 & 28.55736 & \multirow{2}{*}{2.991} & \multirow[t]{2}{*}{48} & \multirow[t]{2}{*}{0.004} \\
\hline & Intra venous & 23 & 83.66753 & 35.35046 & & & \\
\hline \multirow[t]{2}{*}{ Blood Volume } & Intra articular & 10 & 4.328865 & 0.761773 & \multirow{2}{*}{$\begin{array}{c}- \\
0.361\end{array}$} & \multirow[t]{2}{*}{16} & \multirow[t]{2}{*}{0.723} \\
\hline & Intra venous & 8 & 4.445063 & 0.552154 & & & \\
\hline \multirow[t]{2}{*}{ Haemoglobin Loss } & Intra articular & 10 & 39.71865 & 32.71405 & \multirow{2}{*}{$\begin{array}{c}- \\
1.786\end{array}$} & 11.816 & \multirow[t]{2}{*}{0.1} \\
\hline & Intra venous & 8 & 75.44928 & 48.44352 & & & \\
\hline \multirow[t]{2}{*}{ Hgbe } & Intra articular & 27 & 10.5 & 1.08557 & \multirow{2}{*}{$\begin{array}{c}- \\
0.429\end{array}$} & \multirow[t]{2}{*}{48} & \multirow[t]{2}{*}{0.669} \\
\hline & Intra venous & 23 & 10.65217 & 1.417382 & & & \\
\hline \multirow[t]{2}{*}{ Height } & Intra articular & 27 & 1.6311 & 0.08021 & \multirow{2}{*}{$\begin{array}{c}- \\
0.276\end{array}$} & \multirow[t]{2}{*}{48} & \multirow[t]{2}{*}{0.784} \\
\hline & Intra venous & 23 & 1.6378 & 0.0919 & & & \\
\hline \multirow[t]{2}{*}{ Weight (kilograms) } & Intra articular & 27 & 70.52 & 11.814 & \multirow[t]{2}{*}{-0.68} & \multirow[t]{2}{*}{42.908} & \multirow[t]{2}{*}{0.5} \\
\hline & Intra venous & 23 & 72.35 & 6.912 & & & \\
\hline \multirow[t]{2}{*}{ Hgbi } & Intra articular & 27 & 11.90741 & 1.282103 & - & 48 & 0.062 \\
\hline & Intra venous & 23 & 12.65217 & 1.473977 & 1.911 & & \\
\hline 0 Hour Haemoglobin & Intra articular & 27 & 11.27407 & 1.208175 & & 48 & 0.501 \\
\hline & Intra venous & 23 & 11.55652 & 1.725959 & 0.678 & & \\
\hline 6 Hours Haemoglobin & Intra articular & 27 & 11.05556 & 1.223279 & - & 48 & 0.211 \\
\hline & Intra venous & 23 & 11.52174 & 1.374097 & 1.269 & & \\
\hline 12 Hours Haemoglobin & Intra articular & 27 & 10.85556 & 1.114013 & - & 48 & 0.326 \\
\hline & Intra venous & 23 & 11.22174 & 1.489953 & 0.993 & & \\
\hline 24 Hours Haemoglobin & Intra articular & 27 & 10.55185 & 1.116096 & - & 48 & 0.397 \\
\hline & Intra venous & 23 & 10.86087 & 1.440562 & 0.854 & & \\
\hline
\end{tabular}


Comparison of the Blood Loss in $\mathrm{ml}$ between the two groups shows that Blood Loss in $\mathrm{ml}$ is higher in INTRA VENOUS group with a $t$ value of -2.843 and is statistically significant with a p value of 0.007 .

Comparison of the $\mathrm{Hb}$ loss between the two groups shows that $\mathrm{Hb}$ loss is higher in INTRA VENOUS group with a $\mathrm{t}$ value of -2.991 and is statistically significant with a p value of 0.004 .

\section{Discussion}

A Published report from October 2006 to March 2015 shows a total of 91,772 cases of total knee arthroplasty (TKA) with the average patient aged 64.31 years. Total knee arthroplasty is a commonly used treatment modality for end stage knee disorders such as Osteoarthritis (95\%) and Rheumatoid arthritis (2\%). ${ }^{4}$

The Geriatric patient poses a unique challenge to the operating surgeon, there is a need to successfully rehabilitate these patients and return them to their normal condition as soon as possible in order to reduce their morbidity. Total knee arthroplasty provides the patients relief from pre-operative symptoms. Lower limb arthroplasty surgeries are associated with high degrees of blood loss; TKA is associated with blood loss ranging from 1,000 to $1,500 \mathrm{ml}^{5}$, which has a significant influence on morbidity and mortality. Perioperative transfusion of blood products, besides being an extremely expensive procedure also places the recipient at an increased risk of infection, immune suppression, allergies, transfusion related pulmonary injury and transmission of viral pathogens. This leads to a longer duration of hospital stay and increased hospital charges. ${ }^{6-8}$

Orthopaedic surgeons have therefore tended to minimize the use of allogenic blood transfusion. Autologous transfusion, cryotherapy, hypotensive anaesthesia, fibrin glue and erythropoietin alpha have been studied in this regard. ${ }^{9-12}$

Antifibrinolytics are a class of drugs that have been in use since the 1960s. TXA is an analog of the amino acid lysine. It acts through competitive inhibition of plasminogen activation and plasmin binding to fibrin. It supports the ongoing coagulation by preventing the breakdown of formed fibrin.

Tranexamic acid has been used successfully in Orthopaedic surgery via intravenous and intraarticular routes and has shown significant results bleeding and rates of transfusion following lower limb arthroplasty. Isolated reports have noted the risk of thromboembolic complications after systemic administration.

Akizuki et $\mathrm{al}^{13}$ first reported intraarticular use of TXA in Orthopaedic surgery in 1997. They reported no signs of post-operative blood transfusion in 64 unilateral cementless TKA patients. Intraarticular TXA can directly target the site of bleeding within the joint cavity. It reduces the marked increase in local fibrinolysis after release of tourniquet and increases microvascular haemostasis. Based on the findings in a study done by Paphon Sa-ngasoongsong et $\mathrm{al}^{14}$, the systemic absorption of TXA from a closed joint cavity with a clamped drain was highest at 2 hours and gradually declined until 12 hours. This was attributed to blockage of TXA absorption by increased clot formation on the surgical bed. After clot formation has been established, minimal or no systemic absorption occurs. Intraarticular application leads to $70 \%$ lower systemic absorption and is therefore a safer alternative than for it to be administered systematically.

Senthil et a ${ }^{15}$ argue that $84 \%$ postoperative blood loss of TKA occurs in the first 12 hours after surgery and in theory, closing the drainage tube at the early stages can increase the intra-articular pressure, thereby reducing the bleeding and any post-operative hidden hemorrhage. Hidden hemorrhage refers to perioperative period hemoglobin loss caused by extravasation in the tissue gap and missing in the joint cavity together with hemolysis. The hemoglobin balance method used by us, takes into consideration the amount of hidden blood loss that cannot be directly measured by drain output.

Katsumata et al. ${ }^{16}$ showed that tourniquet usage in limb operation could activate fibrinolysis system, leading to continued hemorrhage after surgery.

Wong et al ${ }^{17}$ performed a study with 124 knees and reported reduced postoperative blood loss after TKA when TXA was applied intraarticular before wound closure. Seo et $\mathrm{al}^{18}$ reported a comparison between intravenous TXA, intraarticular TXA, and placebo in TKA. They noted a decreased blood loss and transfusion requirements in both TXA groups, with larger decreases seen with intraarticular TXA. Gandhi et $\mathrm{al}^{19}$ suggested that TXA can be considered for routine use in primary TKA and THA. Tan et $\mathrm{al}^{20}$ showed that intravenous TXA could significantly reduce blood loss and blood transfusion requirements in primary unilateral TKA, without increasing the risk of venous thromboembolism. Kim et $\mathrm{al}^{21}$ demonstrated that both systemic and topical administration reduced blood loss after TKA.

Niall P Mc Goldrick et a ${ }^{22}$ noted a considerable cost saving in terms of transfusion cost and hospital bed days used, in cases where TXA was used to provide hemoprophylaxis.

\section{Conclusion}

In our study, we conclude that intra articular administered tranexamic acid along with a postoperative 3 hour drain clamping is more effect in providing hemoprophylaxis.

On noting the possible complications that can occur in systemic administered antifibrinolytic in the geriatric population, we advocate an intraarticular administration of tranexamic acid. 


\section{References}

1. Geriatric Orthopaedic Surgery \& Rehabilitation: The Imminent Silver Tsunami and the Need for a New Journal. SAGE publications. 2010;1(1):5.

2. Good L, Peterson E, Lisander B. Tranexamic acid decreases external blood loss but not hidden blood loss in total knee replacement. Br J Anaesth. 2003;90(5):596599.

3. Nadler SB, Hidalgo JH, Bloch T. Prediction of blood volume in normal human adults. Surgery. 1962;51(2):224-232.

4. Indian Society of Hip \& Knee Surgeons joint registry outcome (October 2006 to March 2015).

5. Panteli M, Papakostidis C, Dahabreth Z, Giannoudis PV. Topical tranexamic acid in total knee replacement: a systematic review and meta-analysis. Knee. 2013;20:300309.

6. Rawn J. The silent risks of blood transfusion. Curr Opin Anaesthesiol. 2008;21:664-668.

7. Bierbaum BE, Callaghan JJ, Galante JO, Rubash HE, Tooms RE, Welch RB. An analysis of blood management in patients having a total hip or knee arthroplasty. J Bone Joint Surg Am. 1999;81:2-10.

8. Moonen AF, Neal TD, Pilot P. Peri-operative blood management in elective orthopedic surgery. A critical review of literature. Injury. 2006;37Suppl5:S11-S16.

9. Sehat KR, Evans RL, Newman JH. Hidden blood loss following hip and knee arthroplasty. Correct management of blood loss should take hidden loss into account. J Bone Joint Surg Br. 2004;86:561-565.

10. Pedersen AB, Mehnert F, Overgaard S, Johnsen SP. Allogenic blood transfusion and prognosis following total hip replacement: a population based follow up study. BMC Musculoskeletal Disord. 2009;10:167.

11. Juelsgaard P, Larsen UT, Sorensen JV, Madsen F, Soballe K. Hypotensive epidural anaesthesia in total knee replacement without tourniquet: reduced blood loss and transfusion. Reg Anesth Pain Med. 2001;26:105-110.

12. Bediar H, Yang J, Dwyer MK, McCarthy JC. Preoperative erythropoietin alpha reduces postoperative transfusions in THA and TKA but may not be costeffective. Clin Orthop Relat Re. 2015;473:590-596.

13. Akizuki S, Yasukawa Y, Takizawa T. A new method of hemostasis for cementless total knee arthroplasty. Bull Hosp Jt Dis. 1997;56(4):222-224.

14. Sa-Ngasoongsong, P., Chanplakorn, P., Wongsak, S., Uthadorn, K., Panpikoon, T., Jittorntam, P., Kawinwonggowit, V. An in Vivo Study of Low-Dose Intra-Articular Tranexamic Acid Application with Prolonged Clamping Drain Method in Total Knee
Replacement: Clinical Efficacy and Safety. BioMed Research International. 2015. doi:10.1155/2015/164206.

15. Senthil Kumar G, Von Arx OA and Ponzo JL. Rate of blood loss over 48 hours following total knee replacement. Knee. 2005;12:307-309.

16. Katsumata S, Nagashima M, Kato K, Tachihara A, Wauke K, Saito S, Jin E, Kawanami O, Ogawa R and Yoshino S. Changes in coagulation-fibrinolysis marker and neutrophil elastase following the use of tourniquet during total knee arthroplasty and the influence of neutrophil elastase on thromboembolism. Acta Anaesthesiol Scand. 2005;49:510-516.

17. Wong J, Abrishami A, El Beheiry H. Topical application of tranexamic acid reduces postoperative blood loss in total knee arthroplasty: a randomized, controlled trial. $J$ Bone Joint Surg Am. 2010;92(5):2503-2513.

18. Seo JG, Moon YW, Park SH, Kim SM, Ko KR. The comparative efficacies of intra-articular and IV tranexamic acid for reducing blood loss during total knee arthroplasty. Knee Surg Sports Traumatol Arthrosc. 2012

19. Gandhi R, Evans HM, Mahomed SR, Mahomed NN. Tranexamic acid and the reduction of blood loss in total knee and hip arthroplasty: a meta-analysis. BMC Res Notes. 2013;6:184.

20. Tan J, Chen H, Liu Q, Chen C, Huang W. A metaanalysis of the effectiveness and safety of using tranexamic acid in primary unilateral total knee arthroplasty. Journal Surg Res. 2013;184:880-887.

21. Kim TK, Chang CB, Kang YG. Clinical value of tranexamic acid in unilateral and simultaneous bilateral TKAs under a contemporary blood-saving protocol: a randomized controlled trial. Knee Surg Sports Traumatol Arthrosc. 2014;22(8):1870-78.

22. McGoldrick NP, Eabhann M O'Connor, Nikos Davarinos, Rose Galvin, John F Quinlan. Cost benefit analysis of the use of tranexamic acid in primary lower limb arthroplasty: A retrospective cohort study. World Journal of Orthopedics. 2015;6(11):977-982.

How to cite this article: Kushalappa K.S, Kumar V, Shetty V, Mathias L. Comparative study between the hemoprophylaxis provided by intra-Articular and intravenous tranexamic acid in total knee arthroplasty. Indian J Orthop Surg. 2018;4(4):316-319. 